\title{
Local temperature and ecological similarity drive distributional dynamics of tropical mammals worldwide
}

\author{
Lydia Beaudrot ${ }^{1,2}$ (D) | Miguel A. Acevedo ${ }^{3}$ (D) | Jean-Philippe Lessard ${ }^{4}$ (D) $\mid$ Alex Zvoleff $^{5}$ (D) | \\ Patrick A. Jansen $^{6,7}$ (D) | Douglas Sheil ${ }^{8}$ (D) | Francesco Rovero ${ }^{9}$ (D) | Timothy O'Brien ${ }^{10}$ | \\ Eileen Larney $^{11}$ (D) | Christine Fletcher ${ }^{12}$ | Sandy Andelman ${ }^{10,13}$ (D) | Jorge Ahumada ${ }^{5,14}$ (D) \\ ${ }^{1}$ Department of BioSciences, Program in Ecology and Evolutionary Biology, Rice University, Houston, Texas \\ ${ }^{2}$ Department of Ecology and Evolutionary Biology and Michigan Society of Fellows, University of Michigan, Ann Arbor, Michigan \\ ${ }^{3}$ Department of Wildlife Ecology and Conservation, University of Florida, Gainesville, Florida \\ ${ }^{4}$ Department of Biology, Concordia University, Montreal, Quebec, Canada \\ ${ }^{5}$ Moore Center for Science, Conservation International, Arlington, Virginia \\ ${ }^{6}$ Center for Tropical Forest Science, Smithsonian Tropical Research Institute, Balboa, , República de Panamá \\ ${ }^{7}$ Department of Environmental Sciences, Wageningen University, Wageningen, The Netherlands \\ ${ }^{8}$ Department of Ecology and Natural Resource Management (INA), Norwegian University of Life Sciences (NMBU), Ås, Norway \\ ${ }^{9}$ Tropical Biodiversity Section, MUSE - Museo delle Scienze, Trento, Italy \\ ${ }^{10}$ Wildlife Conservation Society, Bronx, New York \\ ${ }^{11}$ Centre ValBio, Ifanadiana, Madagascar \\ ${ }^{12}$ Forest Research Institute Malaysia, Kepong, Malaysia \\ ${ }^{13}$ Organization for Tropical Studies, Durham, North Carolina \\ ${ }^{14}$ Center for Biodiversity Outcomes, Arizona State University, Tempe, Arizona
}

\section{Correspondence}

Lydia Beaudrot, Department of BioSciences, Program in Ecology and Evolutionary Biology, Rice University, W100 George R. Brown Hall, 6100 Main Street, P.O. Box 1892, MS-140, Houston, TX 77251.

Email: beaudrot@rice.edu

\section{Present Address}

Francesco Rovero, Department of Biology, University of Florence, Sesto Fiorentino, Italy

Sandy Andelman, Wildlife Conservation Society, Bronx, New York

Editor: Veronique Boucher-Lalonde

\begin{abstract}
Aim: Identifying the underlying drivers of species' distributional dynamics is critical for predicting change and managing biological diversity. While anthropogenic factors such as climate change can affect species distributions through time, other naturally occurring ecological processes can also have an influence. Theory predicts that interactions between species can influence distributional dynamics, yet empirical evidence remains sparse. A powerful approach is to monitor and model local colonization and extinction-the processes that generate change in distributions over time-and to identify their abiotic and biotic associations. Intensive camera-trap monitoring provides an opportunity to assess the role of temperature and species interactions in the colonization and extinction dynamics of tropical mammals, many of which are species of conservation concern. Using data from a pan-tropical monitoring network, we examined how short-term local temperature change and ecological similarity between species (a proxy for the strength of species interactions) influenced the processes that drive distributional shifts.

Location: Tropical forests worldwide.
\end{abstract}

Time period: 2007-2016.

Major taxa studied: Terrestrial mammals. 
Methods: We used dynamic occupancy models to assess the influence of the abiotic and biotic environment on the distributional dynamics of 42 mammal populations from 36 species on 7 tropical elevation gradients around the world.

Results: Overall, temperature, ecological similarity, or both, were linked to colonization or extinction dynamics in 29 populations. For six species, the effect of temperature depended upon the local mammal community similarity. This result suggests that the way in which temperature influences local colonization and extinction dynamics depends on local mammal community composition.

Main conclusions: These results indicate that varying temperatures influence tropical mammal distributions in surprising ways and suggest that interactions between species mediate distributional dynamics.

\section{KEYWORDS}

coexistence, dynamic occupancy modelling, imperfect detection, occupancy-environment association, range shift, species distribution, species interactions

\section{1 | INTRODUCTION}

Across ecosystems and taxa, species distributions shift over time in response to natural conditions and anthropogenic threats. Identifying the underlying drivers of these shifts is critical for predicting the future of biological diversity in a changing world. Because abiotic conditions such as ambient temperature determine the geographic locations where species can persist (Buckley, Hurlbert, \& Jetz, 2012), attempts to predict species distributions often focus on climate associations alone (Pacifici et al., 2015). Other factors such as species interactions and dispersal also influence where species occur (Araujo \& Peterson, 2012). Species often inhabit a subset of the range of abiotic conditions they can tolerate because biotic interactions and dispersal limitation can prevent species from "filling" their potential distributions. (Araujo \& Pearson, 2005; Schloss, Nunez, \& Lawler, 2012; Urban, Zarnetske, \& Skelly, 2013). Moreover, theory predicts that biotic processes such as competition can significantly affect distributional shifts (Brooker, Travis, Clark, \& Dytham, 2007; Urban, Tewksbury, \& Sheldon, 2012); nonetheless, empirical evidence remains sparse (Svenning et al., 2014). In particular, a fundamental premise of biology is that competition between species increases with their ecological similarity (Darwin, 1859; Swenson, 2013). A species may therefore be less likely to colonize areas already occupied by ecologically similar species and more likely to experience local extinction where ecological similarity is high (Diamond, 1975; Strauss, Webb, \& Salamin, 2006). Here, we incorporate ecological similarity as a proxy for the strength of species interactions in empirical, process-based models to simultaneously test the role of temperature, species interactions and their interdependence in local colonization and extinction dynamics.

Identifying the determinants of species distributions involves combining process-based models with high-resolution data over space and time, both of which are often lacking. Instead, most current approaches to understand species distributions rely on correlative models that infer distribution patterns based on occupancy-environment relationships at a single snapshot in time (Pacifici et al., 2015). Such "snapshot approaches" suffer from multiple shortcomings (Araujo \& Peterson, 2012). One key issue is their assumption that observed distributions reflect the entire range of environmental conditions a species can tolerate and therefore that species distributions are in equilibrium (Araujo \& Pearson, 2005). However, this spatial equilibrium assumption is rarely met, in part because of temporal changes in the environment. A more robust alternative approach is to monitor and model local colonization and extinction-the processes that generate distributional shifts over time (Kery, Guillera-Arroita, \& Lahoz-Monfort, 2013; Yackulic, Nichols, Reid, \& Der, 2015). The sequential nature of time-series data enhances inference about causality because effects cannot precede causes (Dornelas et al., 2013).

A crucial challenge for understanding how global patterns of diversity may change under future conditions is to identify how the environment affects local colonization and extinction dynamics of data deficient species. In particular, the extent to which tropical species currently respond to climate remains largely unknown (Lenoir \& Svenning, 2015) but see (Duque, Stephenson, \& Feeley, 2015; Freeman \& Freeman, 2014), in large part because reliable long-term data are lacking, particularly for some of the most threatened species, which include many mammals (Dornelas et al., 2014; Feeley \& Silman, 2011; Schipper et al., 2008). Endothermy-the state of being warm blooded-buffers mammals from changes in temperature (Buckley et al., 2012); most tropical mammals currently experience temperatures within their range of thermal tolerance (Khaliq, Hof, Prinzinger, Bohning-Gaese, \& Pfenninger, 2014). However, temperature increases are projected to push many tropical mammal species beyond their thermoneutral zones this century (Khaliq et al., 2014). Moreover, examining the role of biotic interactions, particularly competitive interactions, in local colonization and extinction, is 
especially important for tropical species because interactions may be stronger in the tropics than at higher latitudes (MacArthur, 1972; Roslin, 2017; Schemske, Mittelbach, Cornell, Sobel, \& Roy, 2009; but see Moles \& Ollerton, 2016; Moles et al., 2011). Accordingly, tropical mammals may be less likely to colonize areas where competitors-larger-bodied species with similar activity patterns and diets (French \& Smith, 2005)-occur than where competitors are absent. Uncovering if and how temperature and species interactions currently influence tropical mammal distributions can provide essential information for modelling future shifts. Lastly, rapid human population growth and the natural resource-based economies of many developing countries subject tropical forests to accelerating rates of deforestation (Margono, Potapov, Turubanova, Stolle, \& Hansen, 2014). Conversion of forested habitat to other land uses is one of the greatest extinction threats for tropical wildlife (Pimm et al., 2014). We therefore investigated whether change in forest cover influenced local colonization-extinction dynamics.

Here, we assess abiotic and biotic drivers of local colonizationextinction dynamics of mammals along elevational gradients in seven tropical forests. We test for occupancy-environment associations with temperature and ecological similarity through time. Elevationa gradients provide a tractable opportunity to study how abiotic and biotic factors drive distributional dynamics (HilleRisLambers, Harsch, Ettinger, Ford, \& Theobald, 2013; Malhi et al., 2010). Background climate often varies systematically along elevational gradients, constituting a natural laboratory to address questions about the role of climate in species distributions (Sundqvist, Sanders, \& Wardle, 2013). Species occurrences can be more comprehensively documented along elevational than latitudinal gradients because of their smaller spatial area. Finally, the shorter distances encompassed by elevational gradients relative to latitudinal gradients largely control for dispersal limitation (Hargreaves, Samis, \& Eckert, 2013).

\section{2 | METHODS}

\subsection{Field sites and data collection}

We analysed over 400,000 camera-trap observations sampled along seven elevational gradients from three continents by the Tropical Ecology Assessment and Monitoring (TEAM) Network (Figure 1). TEAM is a global monitoring network comprised of three core partners (Conservation International, Wildlife Conservation Society, Smithsonian Institution) and numerous academic and local partners. TEAM was established in 2002 to monitor long-term trends in biodiversity, land use and climate in tropical forests throughout the world. TEAM surveys terrestrial (i.e., ground-dwelling) tropical mammal populations on an annual basis, using a standardized protocol with large-scale arrays of permanent camera-trap points (Jansen, Ahumada, Fegraus, \& O'Brien, 2014). This provides fine-grained data replicated over a large spatial extent, which are rarely available in the tropics (Beck et al., 2012). The camera traps also record the temperature each time a photograph is taken, providing local-scale information on temperature in regions of the world for which highresolution climate data are lacking.

We analysed data from seven TEAM study sites that spanned elevation gradients of more than $500 \mathrm{~m}$ (Supporting Information Table S1). These sites were located in tropical forests on three continents (Figure 1). The study sites were: Bwindi Impenetrable Forest (BIF)

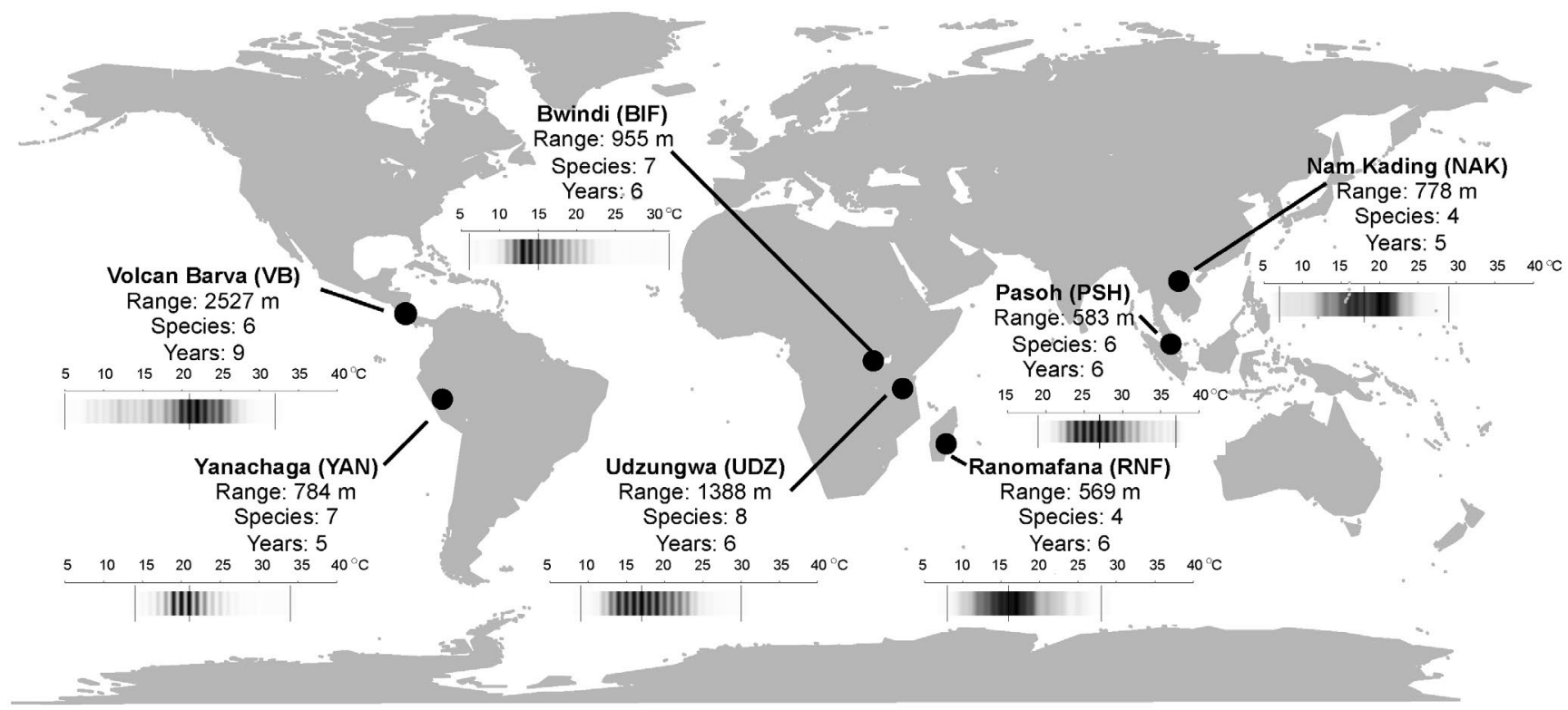

FIG URE 1 Location of seven Tropical Ecology Assessment and Monitoring (TEAM) study sites with elevation ranges $>500 \mathrm{~m}$ sampled by camera traps. Each study site had 60 camera traps at a density of 1 camera per $1-2 \mathrm{~km}^{2}$. The map includes the elevation range in metres, the number of species analysed, the number of years of data and the distribution of camera trap temperature measurements in degrees $C$ for each TEAM study site. Vertical lines within temperature distributions depict the minimum, median and maximum temperature for each TEAM site. See Supporting Information Table S1 for additional site information 
in Uganda, Nam Kading (NAK) in Lao People's Democratic Republic (PDR), Pasoh Forest Reserve (PSH) in Malaysia, Ranomafana (RNF) in Madagascar, Udzungwa (UDZ) in Tanzania, Volcan Barva (VB) in Costa Rica, and Yanachaga- Chimillen National Park (YAN) in Peru. We use the term "site" throughout the paper to refer to these overall TEAM study sites. Individual camera trap sampling points are referred to as sampling points or camera traps. All camera trap data were collected between 2007 and 2016 .

At each study site, 60 camera traps were deployed at a density of 1 camera per 1 or $2 \mathrm{~km}^{2}$ (Supporting Information Table S1). TEAM has defined the sampling units as a grid of $2 \mathrm{~km}^{2}$ cells assuming that animals within the sampling unit have non-zero probabilities of encountering the camera trap given their movement patterns and density (TEAM Network, 2011). Each camera trap was deployed for 30 consecutive days during the dry season, defined as months with $<100 \mathrm{~mm}$ average rainfall, or the drier part of the year at sites with no dry season. Camera trap images were identified by TEAM personnel following the standard International Union for Conservation of Nature (IUCN) Red List (IUCN, 2014) and managed via custom cyberinfrastructure (Baru et al., 2012; Fegraus et al., 2011). TEAM monitors all ground-dwelling and predominately ground-dwelling mammals greater than $100 \mathrm{~g}$ in body mass. Of the 163 mammal populations monitored at these sites, the 62 populations with more than 5 detections annually were examined in this study. For a complete list of species monitored, see Beaudrot et al. (2016).

\section{2 | Occupancy modelling}

We modelled population-specific local colonization and extinction along elevational gradients using dynamic (multi-season) occupancy models (MacKenzie, Nichols, Hines, Knutson, \& Franklin, 2003). This model is an appropriate and robust tool because it accounts for imperfect detection by camera traps (MacKenzie et al., 2006; Royle \& Dorazio, 2008) and makes few assumptions about equilibrium or pseudo-equilibrium (Clement, Hines, Nichols, Pardieck, \& Ziolkowski, 2016). The dynamic occupancy modelling approach has a similar sampling scheme as Pollock's robust design for mark-recapture studies (Pollock, 1982). This design is composed of two sampling periods, primary and secondary, in which a series of detections or non-detections are recorded (Supporting Information Figure S1). Among primary periods the population is allowed to be open for colonization or extinction. Our primary periods consisted of years; thus, colonization and extinction occurred on an annual basis. Secondary periods consisted of 24-hr intervals within the annual 30-day camera-trap sampling period, which we further combined into 6 days of sampling to increase the number of detections per secondary period and aid model convergence. This sampling scheme assumes a population was closed to local colonization and extinction during the 30 day period each year when the camera traps were deployed.

In a dynamic occupancy modelling framework, collecting data during primary and secondary periods allows the ecological process, which is occupancy, to be modelled separately from the observation process, which is detection. Indeed, these processes must be modelled separately to estimate detection probability. The ecological process involves estimating three parameters: initial occupancy probability, local colonization probability and local extinction probability. The observation process involves estimating one parameter: detection probability. Detection probability is important because animals may not be detected even though they are present. Occupancy estimates that do not account for imperfect detection may be biased and underestimate occupancy (MacKenzie, 2006).

The occupancy and observation processes can be modelled as latent and observed random variables such that:

$$
\begin{gathered}
z_{1, i} \sim \operatorname{Bern}\left(\psi_{1}\right) \\
\left(z_{t, i} \mid z_{t-1, i}=0\right) \sim \operatorname{Bern}\left(\gamma_{t-1}\right) \text { for } t=2, \ldots, T, \\
\left(z_{t, i} \mid z_{t-1, i}=1\right) \sim \operatorname{Bern}\left(1-\varepsilon_{t-1}\right) \text { for } t=2, \ldots, T, \\
h_{t, i j} \mid z_{t, i} \sim \operatorname{Bern}\left(z_{t, i} p_{t j}\right)
\end{gathered}
$$

where $z_{t, i}$ represents occupancy in time $t$ at site $i, h_{t, i j}$ the detection history and $p_{t j}$ the probability of detection. These equations describe occupancy as a Bernoulli random process. The probability of occupancy at season $t$ is given by $\psi_{t}$. If the species was not detected in site $i$ in the previous primary period, then the probability of the site being colonized at time $t$ is $\gamma_{t}$. If the species was detected in the previous primary period, then the probability of detecting it again is given by $1-\varepsilon_{t}$ (i.e., one minus the probability of local extinction). The probability that a site is occupied depends upon whether it was occupied in the previous time step, thus dynamic changes in occupancy are treated as a first-order Markov process. Initial occupancy, colonization and extinction can also be modelled using covariates through a logit model of the form logit $\left(\pi_{t}\right)=\beta_{0}+\beta_{1} x_{t}$, where $\pi_{t}$ is a Bernoulli distributed variable that represents initial occupancy $\left(\psi_{t}\right)$, colonization $\left(\gamma_{t}\right)$ or extinction probabilities $\left(\varepsilon_{t}\right)$, and $x_{t}$ represent covariates.

Covariates were selected to test the effects of abiotic and biotic factors on local colonization and extinction. Covariate measurements are described in more detail below. We used two types of covariates: sampling point covariates (Elevation, Forest Loss, Forest Gain, Biotic) and covariates that were both sampling point and timedependent (Tmin, Tmax, Tvar). Sampling point covariates differed between sampling points (i.e., camera traps) but did not change over time. Thus, each camera trap had a single (i.e., constant) value of elevation, forest loss and forest gain for the study. For each population, each camera trap had a single (i.e., constant) biotic value for the study. Sampling point- and time-dependent covariates changed annually between sampling points and between years. Thus, each camera trap had a different annual value for Tmin, Tmax and Tvar. These values were the minimum, maximum and variance of the temperatures recorded at a camera trap during the 30 days of sampling in a year (see details below).

We parameterized the models using maximum likelihood and used Akaike information criterion corrected for small sample size ( $\mathrm{AIC}_{\mathrm{c}}$ ) 
model selection (Burnham \& Anderson, 2002) to test hypothesized relationships between local colonization-extinction dynamics based on the most parsimonious combination of forest cover change, temperature and/or biotic interaction covariates. All models included in the model set are listed in Supporting Information Table S2. We used an intercept-only model (no covariates) as a null dynamic occupancy model. For initial occupancy, we conducted model selection with and without elevation as a covariate because whether a site was occupied at the beginning of the study may vary with elevation for some species but not others. That is, some species may be more likely to occur at certain elevations whereas other species may be equally likely occur at all elevations. For detection, models contained forest cover change, temperature and/or biotic interaction as covariates. We included covariates of colonization and extinction as covariates for detection because variation in abundance can be a chief determinant of detection probability (Royle \& Nichols, 2003). We modelled both linear and quadratic terms for elevation and temperature covariates because a range of ideal conditions for a species could result in non-monotonic relationships (e.g., initial occupancy or colonization is highest at intermediate temperatures).

Colonization and extinction were modelled as single parameters rather than year-specific parameters. We explored year effects on colonization and extinction in an attempt to explore non-stationarity (i.e., that occupancy is not approaching equilibrium). However, models with year effects, except for a small number of populations, did not converge.

We used condition numbers as a way to ensure adequate model fit. Condition numbers provide data on how much information is lost when a problem is solved numerically rather than analytically. Models with a condition number $>10^{4}$ are indicative of parameters that are unidentifiable or models with optimization problems (Cheney \& Kincaid, 2008 , p. 640). Therefore, we chose the combination of a condition number $<5,000$ and small standard errors as a conservative way of selecting models with which to make inferences in this study. This ensured that the model selected through AICc model selection had an appropriate fit to the data. Populations were included in our results if the null model and at least one non-null model had a condition number less than 5,000. Odds ratios were used to interpret the strength of local colonization and extinction covariates in the best model of each population. All modelling was conducted in R using the library "unmarked" (Fiske \& Chandler, 2011; R Development Core Team, 2016).

\subsection{1 | Forest cover change}

Hansen et al. (2013) used Landsat images to produce a global dataset characterizing forest extent and change (i.e., loss or gain) at a $30 \mathrm{~m}$ resolution. We used the Global Forest Change product from Hansen et al. (2013) and applied a 75\% threshold to the 2000 forest cover layer to produce a forest/non-forest map for the year 2000. We took into account the forest loss layers in the product to calculate forestnon-forest maps for each camera-trap location for the 5 years prior to the onset of camera-trap monitoring. We calculated the percent of forest lost in a 30,60 and $120 \mathrm{~m}$ buffer surrounding each camera trap location to quantify forest cover change because we were interested in the role of local change (Supporting Information Figure S2). Because camera traps were deployed at a density of 1 camera per 1 or $2 \mathrm{~km}^{2}$, buffers of larger sizes that overlapped between camera traps would not provide meaningful information. To capture the greatest variation in forest cover, we used the $120 \mathrm{~m}$ buffer for camera trap specific forest cover loss as a covariate of local colonization, extinction and detection in the dynamic occupancy models. We also calculated percent forest gain over the 2000-2012 period for the buffers around each camera. We used the $120 \mathrm{~m}$ buffer of forest gain as a covariate of local colonization, extinction and detection (Supporting Information Table S2).

\subsection{2 | Temperature and elevation}

We considered three aspects of temperature on local colonization and extinction that have been shown to influence distributions of other taxa: temperature minimum ( $T_{\min }$; Warren \& Chick, 2013), temperature maximum ( $T_{\text {max }}$; Welbergen, Klose, Markus, \& Eby, 2008) and temperature variance ( $\mathrm{T}_{\mathrm{var}}$; Thompson, Beardall, Beringer, Grace, \& Sardina, 2013). Temperature measurements were taken from the camera traps during times of active sampling, providing highly local, site-specific temperature data with a precision of $1 \mathrm{C}$ every time a camera was triggered. The temperature data measured conditions at each camera trap during times of animal activity and are thus biased against conditions that animals avoided. Because both the precision of the data and potential bias towards animal activity reduce the likelihood of detecting responses to temperature, this approach produced conservative results.

We inspected the temperature data and removed outliers that indicated faulty temperature sensors (i.e., $>40^{\circ} \mathrm{C} ; n=3$ cameras). Faulty temperature sensors within the normal temperature range would have been undetected. We then calculated the temperature minimum, maximum and variance for each year at each camera trap sampling point using camera trap specific temperature records. We used these sampling point- and time-dependent measurements as covariates of local colonization, local extinction and detection.

We also calculated temperature trends to assess patterns in temperature change over time at the seven TEAM sites. Specifically, we calculated the trend in temperature for each camera trap at each TEAM site. We ran a linear regression for the annual temperature values at each camera trap as a function of time. We then extracted the slope of the linear regression and used this as the temperature trend for a camera trap. To examine whether temperature trends showed consistent warming at a TEAM site, we plotted the distribution of camera trap specific trends per TEAM site (Figure 2).

Elevation data were extracted from the void filled Shuttle Radar Topography Mission (SRTM) digital elevation model $[90 \mathrm{~m}$ resolution with vertical accuracy of 4-7 m (Gorokhovich \& Voustianiouk, 2006)] from the Consortium for Spatial Information (CGIAR-CSI; Jarvis, Guevara, Reuter, \& Nelson, 2008) for the geographic coordinates of each camera trap. 


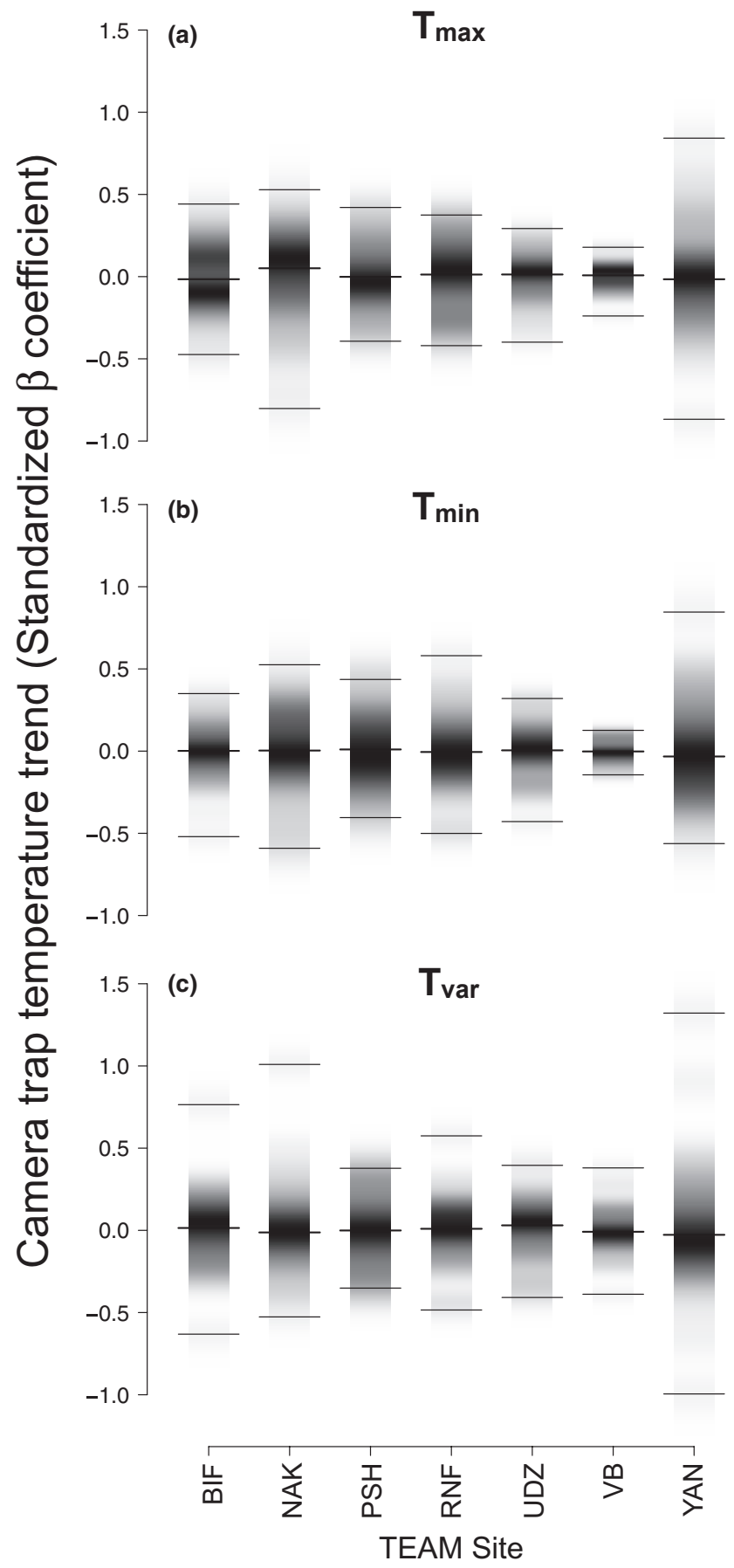

FIGURE 2 Distribution of temperature trends at individual camera traps. Each camera trap recorded the temperature when it took a photograph, providing highly local, camera trap-specific temperature data. We show the distribution of slopes of temperature trends over time for each of the 60 camera traps at each of the seven Tropical Ecology Assessment and Monitoring (TEAM) sites for temperature (a) maximum, (b) minimum and (c) variance. Temperature did not change during the study period at TEAM sites overall. However, temperature changed over time at many individual camera traps. Darker shading depicts higher densities of camera traps with a given temperature trend. Black tick lines indicate the minimum, median and maximum trend for each variable and site. Median values at zero indicate the lack of an overall temperature trend at the TEAM site level. The extent of variation in positive and negative trends, shown by the variances in the distributions, denotes temperature increases and decreases during the study period at the local camera trap scale. An individual temperature trend was calculated as the slope of a linear regression of temperature values over time at a camera trap. Standardized beta coefficients from the linear regressions are shown. Three-letter TEAM site codes correspond to Figure 1 


\subsection{3 | Ecological similarity of local mammal community composition}

We tested for potential species interactions by including an index of ecological similarity as a predictor of local colonization and extinction dynamics. In the absence of direct information on competitive interactions, measures of ecological similarity-namely, ecological traits such as diet, body size and activity pattern, and the degree of evolutionary relatedness in local communities (Cadotte, Albert, \& Walker, 2013; Cavender-Bares, Kozak, Fine, \& Kembel, 2009; Uriarte et al., 2010)-can serve as a proxy of the amount of biotic resistance encountered as distributional dynamics occur.

For each camera-trap point at each TEAM site and for each species, we computed an ecological similarity index between the focal species being modelled and all other mammal species observed at the camera-trap point. This index combined phylogenetic and functional trait distances in a single, continuous index (Cadotte et al., 2013). We chose to combine phylogenetic and functional trait information because phylogenies and traits can provide different and sometimes complementary information. By combining the two sources of information together, we sought to overcome the weaknesses of each individual approach (Cadotte et al., 2013).

We used a phylogenetic tree of mammals (Fritz, Bininda-Emonds, \& Purvis, 2009) to estimate phylogenetic distances between all pairs of species observed at each TEAM site. Because this phylogenetic tree was not fully resolved, we used a set of 100 trees wherein polytomies were randomly resolved (Kuhn, Mooers, \& Thomas, 2011). Then branch lengths were averaged over these 100 trees to create a pairwise matrix of phylogenetic distances.

To estimate functional-trait distances, we used trait data on body size and dietary guild from Beaudrot et al. (2016), data on activity pattern from PanTHERIA (Jones et al., 2009) and the R package "FD" (Laliberté, Legendre, \& Shipley, 2014). Body-mass data were continuous (in grams) whereas dietary-guild data (herbivore, omnivore, insectivore or carnivore) and activity pattern data (diurnal only, nocturnal only, other) were categorical. We calculated a Gower-distance matrix because the Gower-distance can integrate continuous and categorical data into a single-distance metric (Gower, 1971). The body mass, dietary-guild and activity pattern data were weighted equally in the Gower-distance matrix.

We combined the phylogenetic (PDist) and functional-trait-distance (FDist) matrices into a single-distance matrix (FPDist) weighing the two input matrices equally (Cadotte et al., 2013) such that:

$$
\text { FPDist }=\left(a P D i s t^{p}+(1-a) \text { FDist }^{p}\right)^{1 / p},
$$

where $a$ and $p$ are weighting factors (Cadotte et al., 2013). We used $a=0.5$ to weight the phylogenetic and functional trait distances evenly in the FPDist calculation. We used $p=2$ to calculate a Euclidean distance from the combined functional and phylogenetic distances.

One shortcoming of functional and phylogenetic distances is that they are sensitive to variation in species richness (i.e., in the local community size). We therefore standardized FPDist for our ecological dissimilarity index (EDI) to eliminate the sensitivity to variation in species richness [see Uriarte et al. (2010) for a similar approach]. To standardize the EDI, we created null models wherein artificial communities were simulated and their EDI recalculated each time. For each species and community combination, we generated 1,000 simulated EDI values. The standardized EDI was calculated using the following formula:

$$
-\left(\mathrm{EDI}_{\mathrm{obs}}-\text { mean }_{\mathrm{EDI}} \mathrm{null}_{\mathrm{l}} / \mathrm{SDEDI} \mathrm{I}_{\text {null. }}\right)
$$

We used the mean distance between the focal species and the other species observed at a camera trap as a covariate of local colonization, local extinction and detection. Positive values for the standardized index indicate ecological dissimilarity, whereas negative values indicate ecological similarity.

Dendrograms illustrate the ecological similarity measured within mammal communities at each TEAM site (Supporting Information Figure S2). We used the unweighted pair group method with arithmetic mean (UPGMA) clustering method, which calculates the mean distance between clusters as the distance between each cluster point and all other points in a different cluster. A new cluster forms from the two clusters with the lowest mean distance (Fielding, 2007). Species that are more ecologically similar at a TEAM site are closer together in the site-level dendrograms.

\section{3 | RESULTS}

Forty-two populations representing 36 species had sufficient data for successful model convergence (Supporting Information Table S3). Of these 42 populations, the null model (without covariates) was the best model for 13 populations. Twenty-nine populations had best models with biotic and/or temperature covariates for local colonization and/or extinction (Table 1). All seven tropical forest study sites had mammal populations with best models containing biotic and temperature covariates for local colonization and/or extinction (Supporting Information Table S1).

TABLE 1 Summary of best models

\begin{tabular}{|l|l|}
\hline Best model & $\begin{array}{l}\text { Number of } \\
\text { populations }\end{array}$ \\
\hline Null & 13 \\
\hline Covariate & 29 \\
\hline Biotic & 2 \\
\hline Temperature & 13 \\
\hline Temperature and biotic & 14 \\
\hline Forest cover change & 0 \\
\hline
\end{tabular}

Note. The number of populations with best-fit models with and without covariates are shown. Supporting Information Table S2 contains the model set and Supporting Information Table S3 contains the best-fit models for each population. 


\section{1 | Forest cover change}

There was little change in forest cover during the period examined, presumably because the camera traps were located within protected areas. Only three of the seven study sites (i.e., BIF, PSH, UDZ) had measurable change in forest loss or gain within a $30 \mathrm{~m}$ buffer of the camera traps (Supporting Information Figure S1). None of the best models for any population contained forest cover change (Table 1).

\section{2 | Temperature}

Temperature trends at individual camera trap locations varied substantially despite a lack of overall study site-level warming during the study period (Figure 2). Local colonization and extinction dynamics of the majority of populations in this study responded to changes in local (i.e., camera trap specific) temperature (Table 1), but the direction and magnitude of this change varied among populations (Figures 3 and 4).

In many instances, odds ratios of local colonization and extinction estimates $( \pm S E)$ indicated that animals were less likely to occupy areas as they warmed. For example, the colonization probability of the black agouti (Dasyprocta fuliginosa, Yanachaga, Peru) decreased on average $3.41 \pm 0.30$ times for a unit increase in scaled minimum temperature. (All interpretations correspond to scaled covariates because covariates were scaled and centred to aide in model convergence.) We found similar patterns in the Central American agouti (Dasyprocta punctata, Volcan Barva, Costa Rica) and Svynnerton's bush squirrel (Paraxerus vexillarius, Udzungwa, Tanzania), which decreased $3.51 \pm 0.31$ and $9.62 \pm 0.12$ times, respectively, for a unit increase in scaled minimum temperature (Figure 3).

Other species were more likely to go locally extinct with increasing temperatures. For example, the Malagasy civet (Fossa fossana, Ranamofana, Madagascar) and ring-tailed coati (Nasua nasua, Yanachaga, Peru) were $1.8 \pm 1.88$ times and $3.72 \pm 3.46$ times, respectively, more likely to go locally extinct with a unit increase in scaled minimum temperature. Furthermore, the African giant pouched rat (Cricetomys gambianus, Udzungwa, Tanzania) was 2.32 \pm 0.97 times more likely to go locally extinct with a unit increase in scaled maximum temperature. These results suggest that a number of tropical mammal populations moved away from warmer microhabitat conditions.

In other cases, areas that got hotter were more likely to be occupied. For instance, the colonization probability of the lesser mouse-deer (Tragulus kanchil, Nam Kading, Lao PDR) increased 1.32 \pm 1.23 times with a unit increase in scaled maximum temperature. We found a similar pattern for the red brocket (Mazama americana, Yanachaga, Peru), bushpig (Potamochoerus larvatus, Udzungwa, Tanzania), chimpanzee (Pan troglodytes, Bwindi, Uganda) and L'hoesti's monkey (Cercopithecus Ihoesti, Bwindi, Uganda), which were $2.38 \pm 1.26,2.21 \pm 1.31,1.43 \pm 0.49$ and $1.30 \pm 0.61$ times, respectively, more likely to colonize a site with a unit increase in scaled maximum temperature. Local extinction decreased $1.59 \pm$ 0.42 times for the Asiatic brush-tailed porcupine (Atherurus macrourus, Nam Kading, Lao PDR), $1.65 \pm 0.52$ times for the lowland paca (Cuniculus paca, Volcan Barva, Costa Rica) and $3.70 \pm 0.22$ times for the black-fronted duiker (Cephalophus nigrifrons, Bwindi, Uganda) with a unit increase in scaled minimum temperature. The probability of extinction also decreased $2.11 \pm 0.45$ times for the bushy-tailed mongoose (Bdeogale crassicauda, Udzungwa, Tanzania) and $29.10 \pm 0.08$ times for the chimpanzee (Pan troglodytes, Bwindi, Uganda) with a unit increase in scaled maximum temperature (Figure 4).

As scaled local temperature variance increased by one unit, local colonization increased $16.67 \pm 26.45$ times for the African golden cat (Caracal aurata, Bwindi, Uganda) and $2.80 \pm 4.25$ times for the common treeshrew (Tupaia glis, Pasoh, Malaysia). In contrast, local colonization declined $2.66 \pm 0.40$ times for the tayra (Eira barbara, Yanachaga, Peru) and $210.66 \pm 0.017$ times for the collared peccary (Pecari tajacu, Volcan Barva, Costa Rica) (Figure 3). For lesser mouse deer (Tragulus kanchil, Pasoh, Malaysia), local extinction decreased $8.40 \pm 0.20$ times as scaled temperature variance increased one unit (Figure 4). These findings reinforce the importance of accounting for temperature variability when modelling species distributions (Vasseur et al., 2014).

\section{3 | Ecological similarity}

Competition with ecologically similar species influenced local extinction dynamics for some species. Black-fronted duiker (Cephalophus nigrifrons, Bwindi, Uganda) and Malagasy civet (Fossa fossana, Ranamofana, Madagascar) were $3.49 \pm 0.22$ and $4.57 \pm 0.22$ times, respectively, more likely to experience local extinction in areas occupied by ecologically similar species-their potential competitors (Figure 4).

Other species were more likely to colonize areas already occupied by ecologically similar species. For instance, lowland paca (Cuniculus paca, Yanachaga, Peru), chimpanzees (Pan troglodytes, Bwindi, Uganda), Asiatic brush-tailed porcupine (Atherurus macrourus, Pasoh, Malaysia), L'Hoesti's monkey (Cercopithecus Ihoesti, Bwindi, Uganda) and lesser mouse-deer (Tragulus kanchil, Nam Kading, Lao PDR) were $1.77 \pm 0.61,3.06 \pm 0.38,5.61 \pm 0.25,6.85 \pm 0.15$ and $4.36 \pm 0.20$ times, respectively, more likely to colonize areas with ecologically similar species (Figure 3). Furthermore, chimpanzee (Pan troglodytes, Bwindi, Uganda), bushpig (Potamochoerus larvatus, Bwindi, Uganda) and lowland paca (Cuniculus paca, Volcan Barva, Costa Rica) were $550.54 \pm 3127,16.62 \pm 17.34$ and $2.06 \pm 1.20$ times, respectively, less likely to go locally extinct in areas occupied by ecologically similar species (Figure 4).

\subsection{Synergistic effects of temperature and ecological similarity}

For six species, local colonization-extinction dynamics were contingent on both temperature and ecological similarity (i.e., the best 
$1.0-$
$0.8-$
$0.6-$
$0.4-$
$0.2-$
$0.0-$

Black agouti Dasyprocta fuliginosa (YAN)

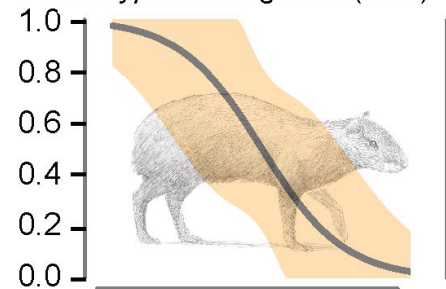

0.0

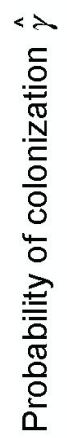
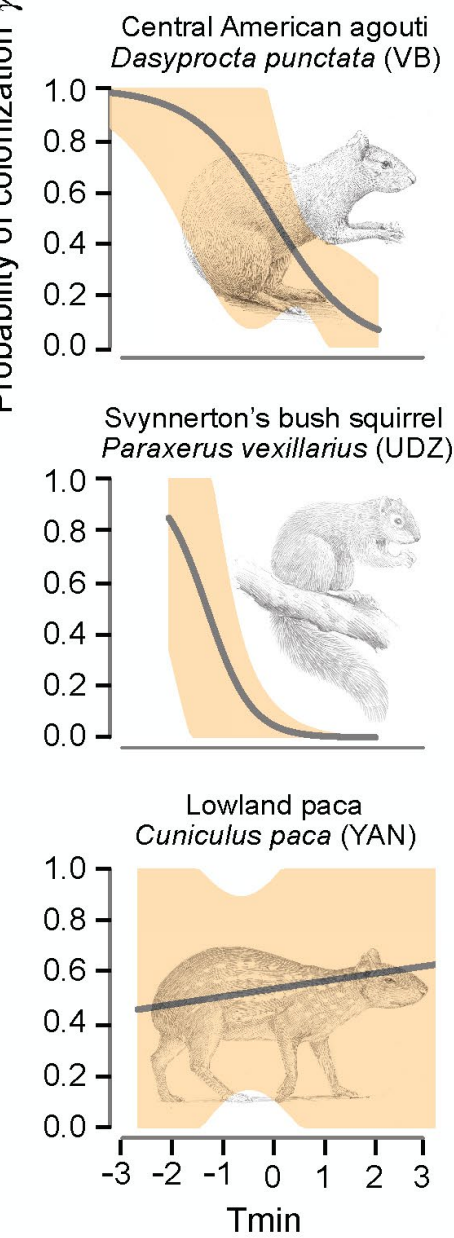
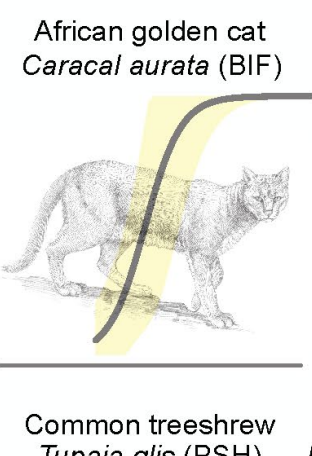

Tupaia glis (PSH)

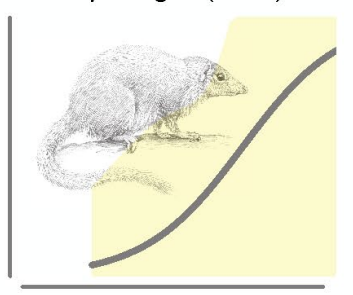

Tayra

Eira barbara (YAN)

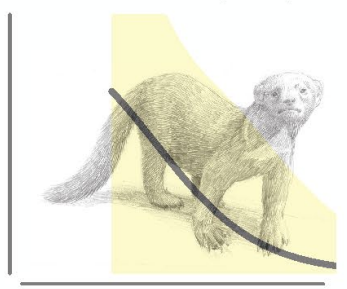

Collared peccary

Pecari tajacu (VB)

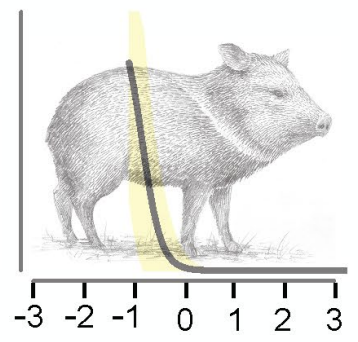

Tvar
Lesser mouse deer Tragulus kanchil (NAK)

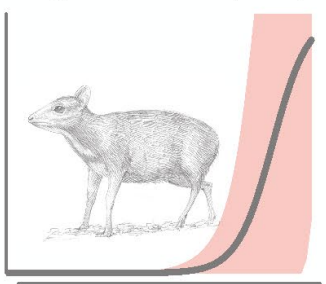

Red brocket Mazama americana (YAN)

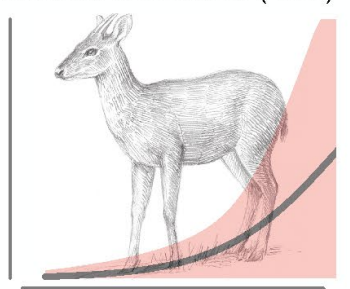

Bushpig

Potamochoerus larvatus (UDZ)

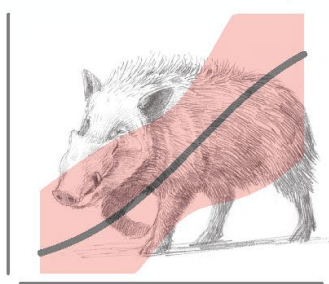

Chimpanzee Pan troglodytes (BIF)

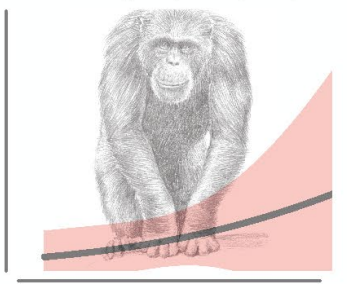

'hoesti's monkey Cercopithecus thoesti (BIF)

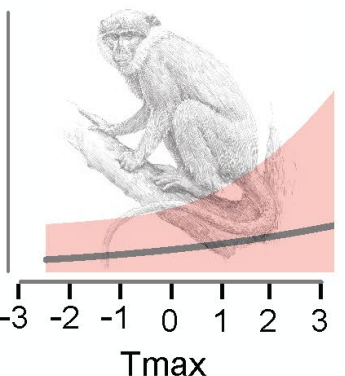

Lowland paca Cuniculus paca (YAN)

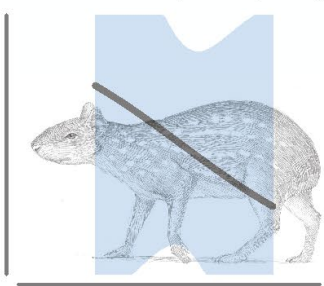

Chimpanzee

Pan troglodytes (BIF)

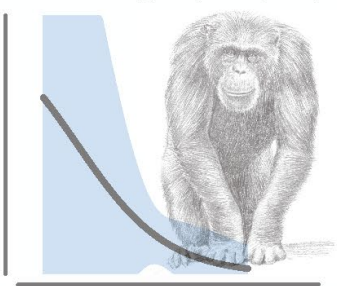

Brush-tailed porcupine Atherurus macrourus (PSH)

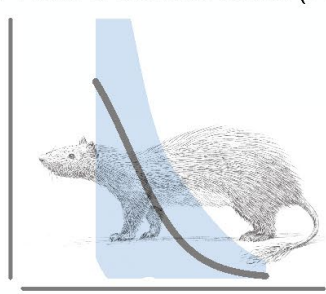

L'hoesti's monkey Cercopithecus Ihoesti (BIF)

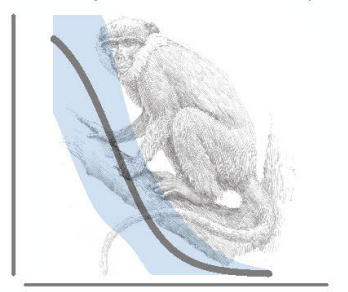

Lesser mouse deer Tragulus kanchil (NAK)

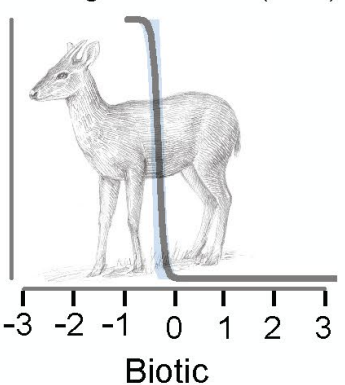

FIGURE 3 Influence of temperature and ecological similarity on local colonization probabilities. Predicted values (black line) and 95\% confidence intervals for temperature minimum (Tmin, light orange shading), temperature variance (Tvar, yellow shading), temperature maximum (Tmax, red shading) and ecological similarity (Biotic, blue shading) for species with top models containing covariates as predictors of local colonization and $\Delta$ Akaike information criterion corrected for small sample size $\left(A_{I C}\right)>2$ from the null model. Variables have been scaled and centred, thus positive and negative values represent increases and decreases from the mean. Positive values for the biotic index indicate ecological dissimilarity of the local mammal community to the focal species, whereas negative values indicate ecological similarity. Three-letter site codes correspond to Figure 1 [Colour figure can be viewed at wileyonlinelibrary.com] 


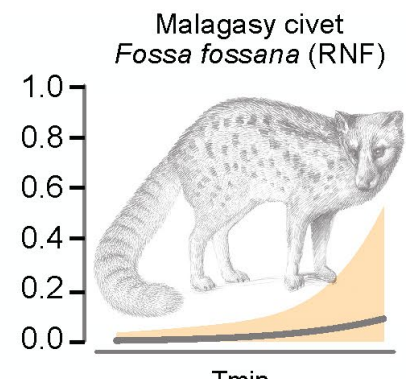

Tmin

South American coati
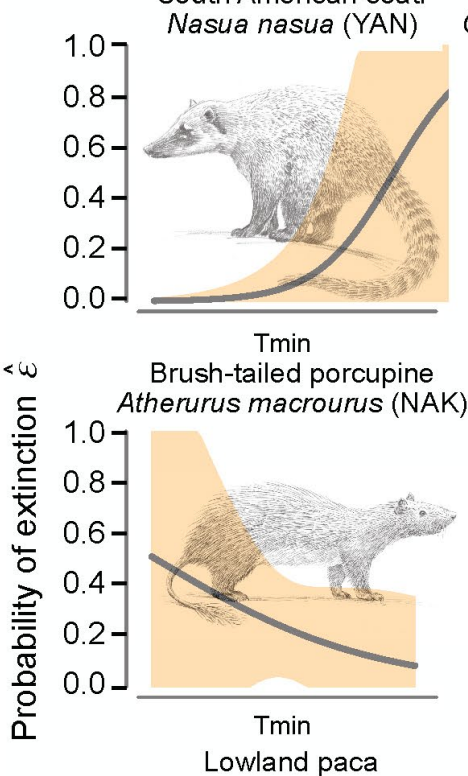

Cuniculus paca (VB)

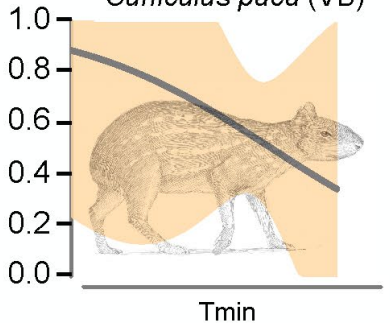

Black-fronted duiker Cephalophus nigrifrons (BIF)

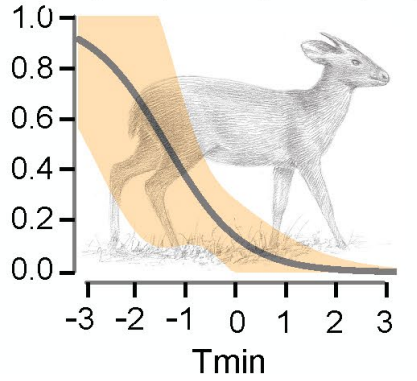

Lesser mouse deer Tragulus kanchil (PSH)

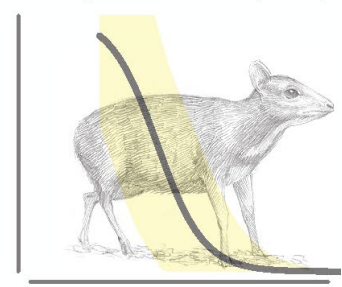

Tvar

African giant pouched rat
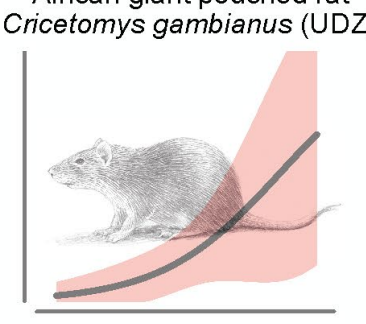

Tmax

Bushy-tailed mongoose
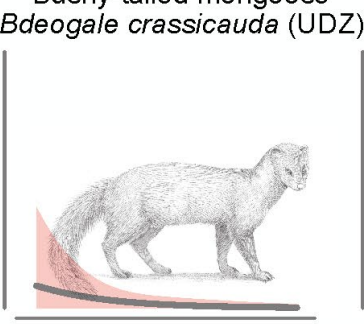

Tmax

Chimpanzee

Pan troglodytes (BIF)

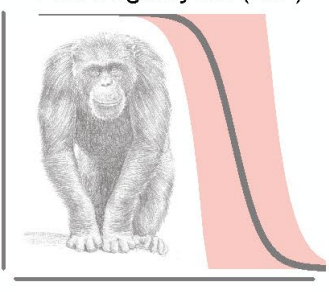

Tmax

South American coati Nasua nasua (YAN)

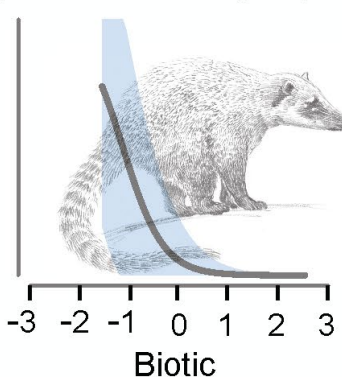

Chimpanzee

Pan troglodytes (BIF)

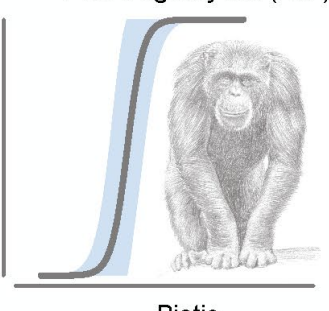

Biotic

Bushpig

Potamochoerus larvatus (BIF)

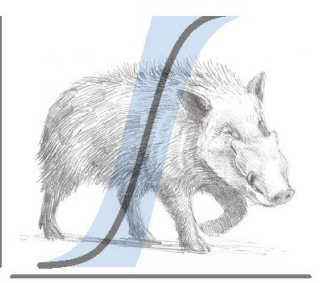

Biotic

Lowland paca Cuniculus paca (VB)

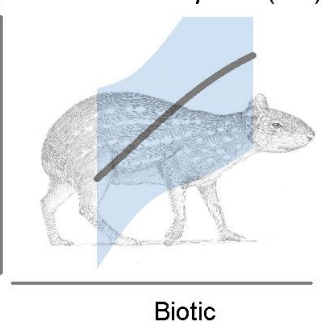

Black-fronted duiker Cephalophus nigrifrons (BIF)

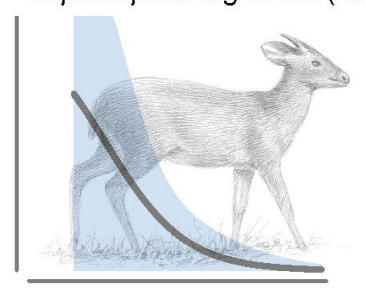

Biotic

Malagasy civet Fossa fossana (RNF)

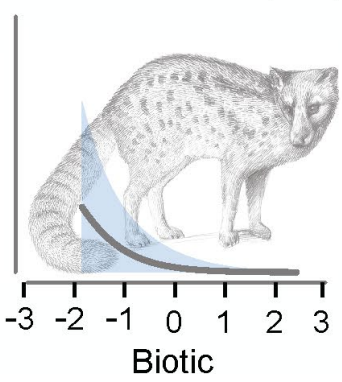

FIGURE 4 Influence of temperature and ecological similarity on local extinction probabilities. Predicted values (black line) and 95\% confidence intervals for temperature minimum (Tmin, light orange shading), temperature variance (Tvar, yellow shading), temperature maximum (Tmax, red shading) and ecological similarity (Biotic, blue shading) for species with top models containing covariates as predictors of local extinction and $\Delta$ Akaike information criterion corrected for small sample size $\left(\mathrm{AIC}_{\mathrm{c}}\right)>2$ from the null model. Variables have been scaled and centred, thus positive and negative values represent increases and decreases from the mean. Positive values for the biotic index indicate ecological dissimilarity of the local mammal community to the focal species, whereas negative values indicate ecological similarity. Three-letter site codes correspond to Figure 1 [Colour figure can be viewed at wileyonlinelibrary.com] 
model contained an interaction term, see Supporting Information Table S3). For these species, the way in which temperature influenced local colonization and extinction dynamics depended on how ecologically similar the local mammal community was to the focal species. Specifically, Sanje mangabey (Cercocebus sanjei, Udzungwa, Tanzania) was less likely to colonize areas with ecologically similar species and more likely to colonize areas with ecologically dissimilar species as temperature variance increased. Red brocket (Mazama temama, Volcan Barva, Costa Rica) and servaline genet (Genetta servalina, Udzungwa, Tanzania) moved into areas with ecologically similar species as maximum temperatures got hotter but colonized areas with ecologically dissimilar species where maximum temperatures cooled over time. As minimum temperatures warmed, Abbott's duiker (Cephalophus spadix, Udzungwa, Tanzania) and yellow-backed duiker (Cephalophus silvicultor, Bwindi, Uganda) were more likely to go locally extinct in areas with ecologically similar species. Lastly, as temperature variance increased, nine-banded armadillo (Dasypus novemcinctus, Volcan Barva, Costa Rica) were more likely to go extinct in areas with ecologically similar species. Nine-banded armadillos were more likely to go extinct in areas with ecologically dissimilar species when local temperatures were more stable (i.e., when temperature variance decreased) (Figure 5).
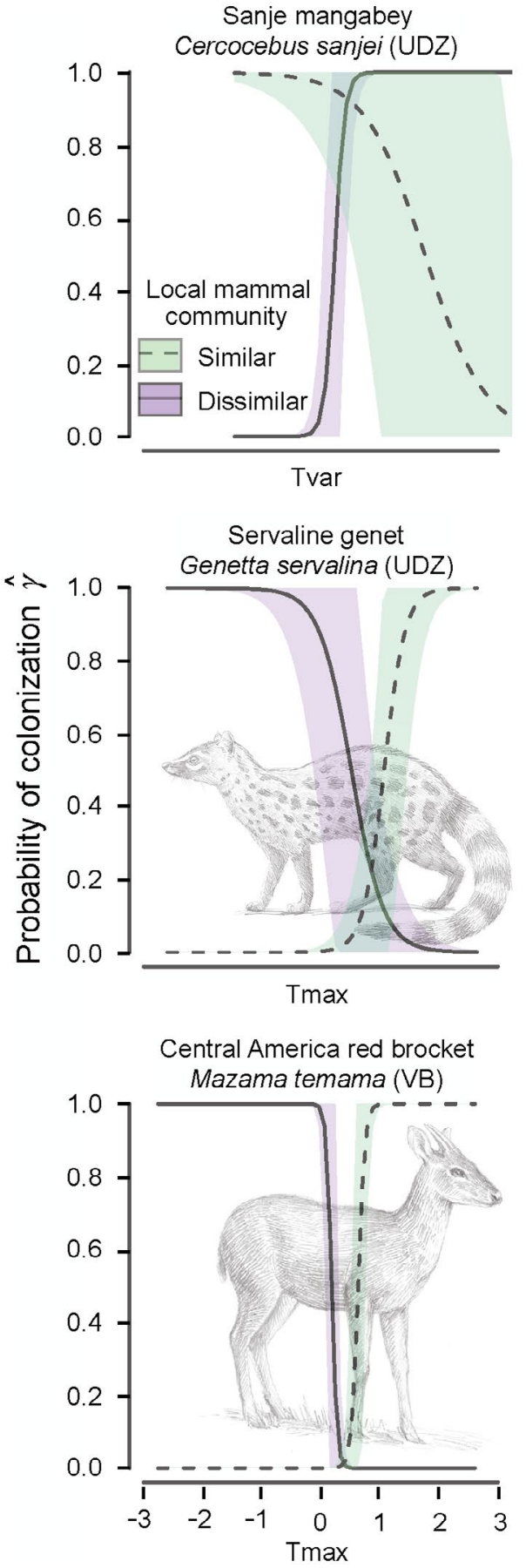

Yellow-backed duiker Cephalophus silvicultor (BIF)

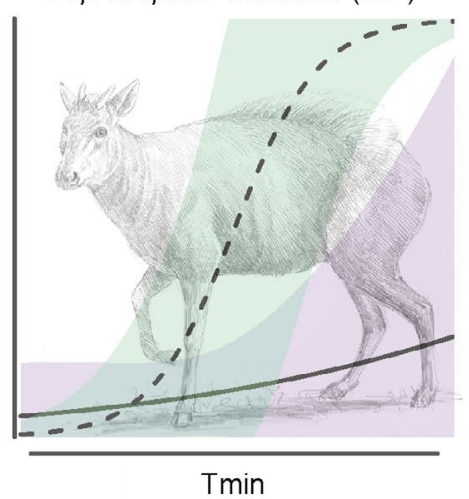

Abbott's duiker Cephalophus spadix (UDZ)

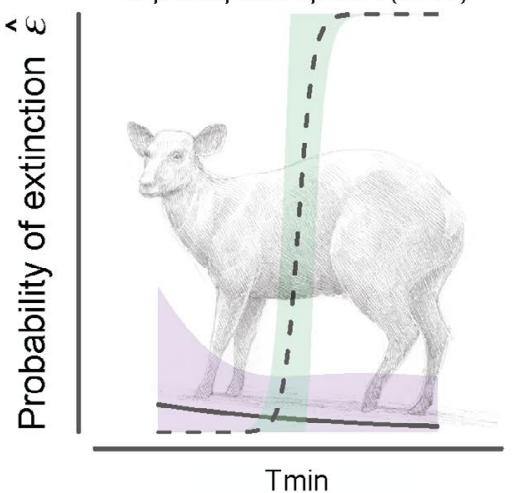

Nine-banded armadillo Dasypus novemcinctus (VB)

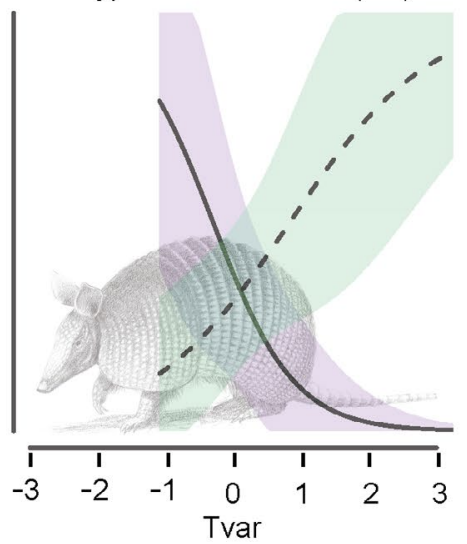

FIGURE 5 Synergistic influences of temperature and ecological similarity on local colonization and extinction dynamics. Local colonization-extinction dynamics were contingent on both temperature and ecological similarity for several species. This figure depicts the interaction terms by showing the effect of ecological similarity on colonization and extinction as temperature changed. For example, Mazama temama was more likely to colonize areas with ecologically similar species as maximum temperature increased, but more likely to colonize areas with ecologically dissimilar species as maximum temperatures decreased. Temperature maximum (Tmax), minimum (Tmin) and variance (Tvar) have been scaled and centred, thus positive and negative values represent increases and decreases from the mean. The green and purple shading show $95 \%$ confidence intervals for the estimates of local colonization in ecologically similar and dissimilar mammal communities, respectively, for two standardized values $(-1,1)$ of the continuous ecological similarity index [Colour figure can be viewed at wileyonlinelibrary.com] 


\section{4 | DISCUSSION}

We tested for the influence of local temperature, ecological similarity and forest cover change as drivers of local colonization and extinction dynamics - the processes underlying distributional shifts-in tropical mammals. We found that local temperature change was associated with important effects on these dynamics for many, but not all, species, and responses to local temperature were highly variable. Moreover, ecological similarity also affected local colonization and extinction dynamics, suggesting that interspecific biotic interactions can act as a barrier (sensu "biotic resistance" (Levine, Adler, \& Yelenik, 2004)) for some tropical mammal species. Nevertheless, we did not find consistent support for the prediction that species would have lower colonization and higher extinction in areas with ecologically similar mammals. Instead, a number of populations had the opposite response: higher colonization and lower extinction probabilities in areas with ecologically similar species. None of the populations responded to change in forest cover, likely because of the small amount of change observed.

Positive species interactions can facilitate colonization and reduce local extinction (Bruno, Stachowicz, \& Bertness, 2003), yet have rarely been considered when examining the drivers of distributional change (Crotty \& Bertness, 2015). In particular, species interactions that improve habitat conditions (i.e., habitat amelioration) or reduce predation (i.e., associational defences) can promote persistence and expand the area where a species occurs (Bertness \& Callaway, 1994). Contrary to our expectation for competition between ecologically similar species, positive interactions with ecologically similar species could have affected distributional dynamics for some species in this study. For example, local extinction probability was lower for both chimpanzees and bushpigs at camera traps with ecologically similar species. Chimpanzees are dominant to other primate species due to their large body size, and have access to the highest nutritional quality fruit when feeding in proximity (Houle, Chapman, \& Vickery, 2010). Chimpanzees may cue in on other primate species feeding as a signal of food availability thereby benefiting from ecologically similar species. As another example, bushpigs are ecologically similar to several primate species at Bwindi in Uganda (Supporting Information Figure S3). They have been observed to forage for fallen fruits under fruiting trees as primates feed and drop fruits to the ground (Ghiglieri et al., 1982). Bushpigs can therefore benefit from some frugivorous primates via increased access to food.

Importantly, the influence of temperature on local colonization and extinction depended on mammal community similarity for several species, demonstrating that these factors can have synergistic effects. The relative influence of these factors can therefore change depending on the environmental and community context (Lessard, Belmaker, Myers, Chase, \& Rahbek, 2012; Lessard et al., 2016). Furthermore, of the six species for which we modelled populations at multiple TEAM study sites, none exhibited consistent relationships with temperature across study sites (Supporting Information Table S3). Similar inconsistencies in species responses to temperature have also been found for temperate mammals (Rowe et al., 2015). This highlights the context dependency of species responses to changing temperature, potentially due to differences in local community composition. Local mammal communities differed not only between camera traps but also between TEAM study sites. We suggest that differences in local community composition may play an important and often unaccounted for role in influencing distributional dynamics.

That changing temperature and ecological similarity simultaneously and synergistically affected local colonization and extinction dynamics has fundamental implications for climate-change research. Most models still rely on the environmental affinities of species alone to forecast species distributions while ignoring the potential role of biotic interactions (Urban et al., 2016), despite considerable implications (Araujo \& Luoto, 2007; Blois, Zarnetske, Fitzpatrick, \& Finnegan, 2013; Pacifici et al., 2015; Wisz et al., 2013). Very few studies show a direct link between climate change and site-level extinctions, yet changes in species interactions have been a commonly identified proximate driver of site-level extinctions (Cahill et al., 2013). Novel competitors can reduce fitness (Alexander, Diez, \& Levine, 2015) and variation in competitive ability has been shown through simulations to drive site-level extinctions (Urban et al., 2012). While an increasing number of studies incorporate biotic interactions into species distributions models (Record et al., 2018), few studies have provided empirical support for the role of species interactions affecting shifts. The fact that the ecological similarity of the local mammal community influenced the local colonization and extinction dynamics of numerous populations in this study suggests that species interactions likely influence tropical mammal distributions. Our empirical results are consistent with theoretical predictions and simulation studies indicating that interactions between species can affect the colonization of new areas (Brooker et al., 2007; Urban et al., 2012) and therefore indicate that the inclusion of species interactions in species distribution modelling is vital, yet the context dependency of our results highlights the complexities of such requirements.

We documented the drivers of local colonization and extinction dynamics in species of conservation concern, but multiple factors limited our assessment. First, even with intensive sampling most species were rare and insufficient detection of rare species inhibits estimation of occupancy dynamics for many of the species monitored by TEAM (Beaudrot et al., 2016). Second, the time span of this study (5-9 years) is short in comparison with some mammalian life spans. Furthermore, the distributions of some tropical mammals may shift in response to fluctuations in food availability (Marshall, Beaudrot, \& Wittmer, 2014). Changes in temperature and precipitation may trigger phenological changes (Wright, 1996) that modify resource availability and habitat quality, which may ultimately drive local colonization-extinction dynamics. Other unmeasured factors, such as natural disturbance (Sheil, 2016), rainfall, humidity and cloud cover could have also affected local colonization-extinction dynamics. In addition, shared habitat preferences between ecologically similar species may have driven local colonization-extinction dynamics rather than species interactions. Lastly, we did not find an effect of forest cover change, likely because camera traps were located within protected areas, but other forms of anthropogenic 
disturbance at TEAM sites, such as edge effects and hunting, may have affected mammal populations (Hegerl et al., 2017; Mugerwa, Sheil, Ssekiranda, Heist, \& Ezuma, 2013).

We found that the local colonization and extinction dynamics of tropical forest mammals are strongly associated with changes in local temperature and our results further suggest that local mammal-community composition can affect these dynamics. This paper highlights the importance of long-term, standardized studies of mammal communities for understanding the role of species interactions and the environment in distributional dynamics. We conclude that considering the influence of species interactions is essential in climate change projections as they are increasingly incorporated into tropical land management, vulnerability assessments and conservation planning.

\section{ACKNOWLEDGMENTS}

All data in this publication were provided by the Tropical Ecology Assessment and Monitoring (TEAM) Network, a collaboration between Conservation International, the Smithsonian Institution and the Wildlife Conservation Society, and partially funded by these institutions, the Gordon and Betty Moore Foundation, and other donors. We confirm that we adhered to the TEAM data use policy. We thank all current and previous TEAM staff and affiliates, including Eric Fegraus, James McCarthy and Melissa Rosa for technical support. We thank Jordan Bemmels, Chris Dick, Matt Fitzpatrick, Deborah Goldberg and Andy Royle for early feedback; we thank Jim Nichols and several anonymous reviewers for their comments; John Megahan for animal illustrations; Tom Hobbs, Mevin Hooten, Kiona Ogle and Maria Uriarte for the Bayes Workshop for Practicing Ecologists (National Science Foundation (NSF) Award 1145200) where the first three authors met. LB thanks the University of Michigan Department of Ecology and Evolutionary Biology and Michigan Society of Fellows for support.

\section{AUTHOR CONTRIBUTIONS}

LB, MA, JPL and JA conceived the project idea. MA, LB and JPL designed the analysis. PAJ, CF, EL, TO, FR and DS contributed TEAM data. LB, MA, JPL and AZ conducted the analysis. LB, JPL and MA wrote the manuscript with contributions from all the authors.

\section{DATA ACCESSIBILITY}

All TEAM data are freely available. They are available at http://www. teamnetwork.org/data/query and will be available through wildlifeinsights.org in the future.

\section{ORCID}

Lydia Beaudrot (iD https://orcid.org/0000-0001-8135-7519

Miguel A. Acevedo (iD https://orcid.org/0000-0002-8289-1497

Jean-Philippe Lessard (iD https://orcid.org/0000-0002-7236-436X

Alex Zvoleff iD https://orcid.org/0000-0002-6008-4918

Patrick A. Jansen (iD https://orcid.org/0000-0002-4660-0314

Douglas Sheil iD https://orcid.org/0000-0002-1166-6591
Francesco Rovero (iD https://orcid.org/0000-0001-6688-1494

Eileen Larney (iD https://orcid.org/0000-0002-1953-0381

Sandy Andelman iD https://orcid.org/0000-0002-3518-7675

Jorge Ahumada iD https://orcid.org/0000-0003-0953-9101

\section{REFERENCES}

Alexander, J. M., Diez, J. M., \& Levine, J. M. (2015). Novel competitors shape species' responses to climate change. Nature, 525, 515-518. https://doi.org/10.1038/nature14952

Araujo, M. B., \& Luoto, M. (2007). The importance of biotic interactions for modelling species distributions under climate change. Global Ecology and Biogeography, 16, 743-753. https://doi. org/10.1111/j.1466-8238.2007.00359.x

Araujo, M. B., \& Pearson, R. G. (2005). Equilibrium of species' distributions with climate. Ecography, 28, 693-695. https://doi. org/10.1111/j.2005.0906-7590.04253.x

Araujo, M. B., \& Peterson, A. T. (2012). Uses and misuses of bioclimatic envelope modeling. Ecology, 93, 1527-1539. https://doi. org/10.1890/11-1930.1

Baru, C., Fegraus, E. H., Andelman, S. J., Chandra, S., Kaya, K., Lin, K., \& Youn, C. (2012). Cyberinfrastructure for observatory and monitoring networks: A case study from the TEAM Network. BioScience, 62, 667-675. https://doi.org/10.1525/bio.2012.62.7.9

Beaudrot, L., Ahumada, J. A., O'Brien, T., Alvarez-Loayza, P., Boekee, K., Campos-Arceiz, A., ... Andelman, S. J. (2016). Standardized assessment of biodiversity trends in tropical forest protected areas: The end is not in sight. PLoS Biology, 14, e1002357. https://doi. org/10.1371/journal.pbio.1002357

Beck, J., Ballesteros-Meijia, L., Buchmann, C. M., Dengler, J., Fritz, S. A., Gruber, B., ... Dormann, C. F. (2012). What's on the horizon for macroecology? Ecography, 35, 673-683.

Bertness, M. D., \& Callaway, R. (1994). Positive interactions in communities. Trends in Ecology and Evolution, 9, 191-193. https://doi. org/10.1016/0169-5347(94)90088-4

Blois, J. L., Zarnetske, P. L., Fitzpatrick, M. C., \& Finnegan, S. (2013). Climate change and the past, present, and future of biotic interactions. Science, 341, 499-504. https://doi.org/10.1126/science. 1237184

Brooker, R. W., Travis, J. M. J., Clark, E. J., \& Dytham, C. (2007). Modelling species' range shifts in a changing climate: The impacts of biotic interactions, dispersal distance and the rate of climate change. Journal of Theoretical Biology, 245, 59-65. https://doi.org/10.1016/j.jtbi.2006.09.033

Bruno, J. F., Stachowicz, J. J., \& Bertness, M. D. (2003). Inclusion of facilitation into ecological theory. Trends in Ecology and Evolution, 18, 119-125. https://doi.org/10.1016/S0169-5347(02)00045-9

Buckley, L. B., Hurlbert, A. H., \& Jetz, W. (2012). Broad-scale ecological implications of ectothermy and endothermy in changing environments. Global Ecology and Biogeography, 21, 873-885. https://doi. org/10.1111/j.1466-8238.2011.00737.x

Burnham, K. P., \& Anderson, D. R. (2002). Model selection and multimodel inference: A practical information-theoretic approach (2nd ed.). New York, NY: Springer.

Cadotte, M., Albert, C. H., \& Walker, S. C. (2013). The ecology of differences: Assessing community assembly with trait and evolutionary distances. Ecology Letters, 16, 1234-1244. https://doi.org/10.1111/ele.12161

Cahill, A. E., Aiello-Lammens, M. E., Fisher-Reid, M. C., Hua, X., Karanewsky, C. J., Ryu, H. Y., ... Wiens, J. J. (2013). How does climate change cause extinction? Proceedings of the Royal Society B: Biological Sciences, 280, 20121890.

Cavender-Bares, J., Kozak, K. H., Fine, P. V. A., \& Kembel, S. W. (2009). The merging of community ecology and phylogenetic biology. Ecology Letters, 12, 693-715. https://doi.org/10.1111/j.1461-0248.2009. 01314.x 
Cheney, W., \& Kincaid, D. (2008). Numerical mathematics and computing (6th ed.). Belmont, CA: Thompson Brooks/Cole.

Clement, M. J., Hines, J. E., Nichols, J. D., Pardieck, K. L., \& Ziolkowski, D. J. (2016). Estimating indices of range shifts in birds using dynamic models when detection is imperfect. Global Change Biology, 22, 3273-3285. https://doi.org/10.1111/gcb.13283

Crotty, S. M., \& Bertness, M. D. (2015). Positive interactions expand habitat use and the realized niches of sympatric species. Ecology, 96 , 2575-2582. https://doi.org/10.1890/15-0240.1

Darwin, C. (1859). On the origin of species by means of natural selection. London, UK: John Murray.

Diamond, J. M. (1975). Assembly of species communities. In M. L. Cody, \& J. M. Diamond (Eds.), Ecology and evolution of communities (pp. 342444). Cambridge, MA: Harvard University Press.

Dornelas, M., Gotelli, N. J., McGill, B., Shimadzu, H., Moyes, F., Sievers, C., \& Magurran, A. E. (2014). Assemblage time series reveal biodiversity change but not systematic loss. Science, 344, 296-299. https:// doi.org/10.1126/science.1248484

Dornelas, M., Magurran, A. E., Buckland, S. T., Chao, A., Chazdon, R. L., Colwell, J., ... Vellend, M. (2013). Quantifying temporal change in biodiversity: Challenges and opportunities. Proceedings of the Royal Society B: Biological Sciences, 280, 20121931. https://doi. org/10.1098/rspb.2012.1931

Duque, A., Stephenson, P., \& Feeley, K. (2015). Thermophilization of adult and juvenile tree communities in the northern tropical Andes. Proceedings of the National Academy of Sciences USA, 112, 1074410749. https://doi.org/10.1073/pnas.1506570112

Feeley, K. J., \& Silman, M. R. (2011). The data void in modeling current and future distributions of tropical species. Global Change Biology, 17, 626-630. https://doi.org/10.1111/j.1365-2486.2010.02239.x

Fegraus, E. H., Lin, K., Ahumada, J. A., Baru, C., Chandra, S., \& Youn, C. (2011). Data acquisition and management software for camera trap data: A case study from the TEAM Network. Ecological Informatics, 6, 345-353. https://doi.org/10.1016/j.ecoinf.2011.06.003

Fielding, A. H. (2007). Cluster and classification techniques for the biosciences. New York, NY: Cambridge University Press.

Fiske, I. J., \& Chandler, R. B. (2011). Unmarked: An R Package for fitting hierarchical models of wildlife occurrence and abundance. Journal of Statistical Software, 43, 1-23.

Freeman, B. G., \& Freeman, A. M. C. (2014). Rapid upslope shifts in New Guinean birds illustrate strong distributional responses of tropical montane species to global warming. Proceedings of the National Academy of Sciences USA, 111, 4490-4494. https://doi.org/10.1073/pnas.1318190111

French, A. R., \& Smith, T. B. (2005). Importance of body size in determining dominance hierarchies among diverse tropical frugivores. Biotropica, 37, 96-101.

Fritz, S. A., Bininda-Emonds, O. R. P., \& Purvis, A. (2009). Geographical variation in predictors of mammalian extinction risk: Big is bad, but only in the tropics. Ecology Letters, 12, 538-549. https://doi. org/10.1111/j.1461-0248.2009.01307.x

Ghiglieri, M. P., Butynski, T. M., Struhsaker, T. T., Leland, L., Wallis, S. J., \& Waser, P. (1982). Bush pig (Potamochoerus-porcus) polychromatism and ecology in Kibale Forest, Uganda. African Journal of Ecology, 20, 231-236. https://doi.org/10.1111/j.1365-2028.1982. tb00298.x

Gorokhovich, Y., \& Voustianiouk, A. (2006). Accuracy assessment of the processed SRTM-based elevation data by CGIAR using field data from USA and Thailand and its relation to the terrain characteristics. Remote Sensing of Environment, 104, 409-415. https://doi. org/10.1016/j.rse.2006.05.012

Gower, J. C. (1971). General coefficient of similarity and some of its properties. Biometrics, 27, 857-871.

Hargreaves, A. L., Samis, K. E., \& Eckert, C. G. (2013). Are species' range limits simply niche limits writ large? A review of transplant experiments beyond the range. American Naturalist, 183, 157-173. https:// doi.org/10.1086/674525
Hegerl, C., Burgess, N. D., Nielsen, M. R., Martin, E., Ciolli, M., \& Rovero, F. (2017). Using camera trap data to assess the impact of bushmeat hunting on forest mammals in Tanzania. Oryx, 51, 87-97. https://doi. org/10.1017/S0030605315000836

Hansen, M. C., Potapov, P. V., Moore, R., Hancher, M., Turubanova, S. A., Tyukavina, A., ... Townshend, J. R. G. (2013). High-resolution global maps of 21st century forest cover change. Science, 342, 850-853.

HilleRisLambers, J., Harsch, M. A., Ettinger, A. K., Ford, K. R., \& Theobald, E. J. (2013). How will biotic interactions influence climate changeinduced range shifts? Climate Change and Species Interactions: Ways Forward, 1297, 112-125.

Houle, A., Chapman, C. A., \& Vickery, W. L. (2010). Intratree vertical variation of fruit density and the nature of contest competition in frugivores. Behavioral Ecology and Sociobiology, 64, 429-441. https://doi. org/10.1007/s00265-009-0859-6

IUCN. (2014) The IUCN Red List of Threatened Species. Version 2014.1. Retrieved from http://www.iucnredlist.org

Jansen, P. A., Ahumada, J., Fegraus, E., \& O'Brien, T. (2014). TEAM: A standardised camera trap survey to monitor terrestrial vertebrate communities in tropical forests. In P. Meek, \& P. Fleming (Eds.), Camera trapping: Wildlife management and research (pp. 263-270). Collingwood, Australia: CSIRO.

Jarvis, A., Guevara, E., Reuter, H. I., \& Nelson, A. D. (2008). Hole-filled SRTM for the globe: Version 4: Data grid. Web publication/site, CGIAR Consortium for Spatial Information. Retrieved from http://srtm.csi.cgiar.org/

Jones, K. E., Bielby, J., Cardillo, M., Fritz, S. A., O'Dell, J., Orme, C. D. L., ... Purvis, A. (2009). PanTHERIA: A species-level database of life history, ecology and geography of extant and recently extinct mammals. Ecology, 90, 2648-2648. https://doi.org/10.1890/08-1494.1

Kery, M., Guillera-Arroita, G., \& Lahoz-Monfort, J. J. (2013). Analysing and mapping species range dynamics using occupancy models. Journal of Biogeography, 40, 1463-1474. https://doi.org/10.1111/jbi.12087

Khaliq, I., Hof, C., Prinzinger, R., Bohning-Gaese, K., \& Pfenninger, M. (2014). Global variation in thermal tolerances and vulnerability of endotherms to climate change. Proceedings of the Royal Society B: Biological Sciences, 281(1789), 20141097. https://doi.org/10.1098/ rspb.2014.1097

Kuhn, T. S., Mooers, A. O., \& Thomas, G. H. (2011). A simple polytomy resolver for dated phylogenies. Methods in Ecology and Evolution, 2, 427-436. https://doi.org/10.1111/j.2041-210X.2011.00103.x

Laliberté, E., Legendre, P., \& Shipley, B. (2014). FD: Measuring functional diversity from multiple traits, and other tools for functional ecology. $\mathrm{R}$ package version 1.0-12.

Lenoir, J., \& Svenning, J. C. (2015). Climate-related range shifts-a global multidimensional synthesis and new research directions. Ecography, 38, 15-28. https://doi.org/10.1111/ecog.00967

Lessard, J. P., Belmaker, J., Myers, J., Chase, J. M., \& Rahbek, C. (2012). Inferring local ecological processes amid species-pool influences. Trends in Ecology and Evolution, 27, 600-607. https://doi. org/10.1016/j.tree.2012.07.006

Lessard, J. P., Weinstein, B., Borregaard, M. K., Marske, K. A., Rojas, D., McGuire, J. A., ... Graham, C. H. (2016). Process-based species pools reveal the hidden signature of biotic interactions amid the influence of temperature filtering. The American Naturalist, 187, 75-88. https:// doi.org/10.1086/684128

Levine, J. M., Adler, P. B., \& Yelenik, S. G. (2004). A meta-analysis of biotic resistance to exotic plant invasions. Ecology Letters, 7, 975-989.

MacArthur, R. H. (1972). Geographical ecology: Patterns in the distribution of species. New York, NY: Harper and Row.

MacKenzie, D. I. (2006). Modeling the probability of use: The effect of, and dealing with, detecting a species imperfectly. Journal of Wildlife Management, 70, 367-374.

MacKenzie, D. I., Nichols, J. D., Hines, J. E., Knutson, M. G., \& Franklin, A. B. (2003). Estimating site occupancy, colonization, and local extinction when a species is detected imperfectly. Ecology, 84, 2200-2207. https://doi.org/10.1890/02-3090 
MacKenzie, D. I., Nichols, J. D., Royle, J. A., Pollock, K. P., Bailey, L. L., \& Hines, J. E. (2006). Occupancy estimation and modeling: Inferring patterns and dynamics of species occurrence. Amsterdam, The Netherlands: Elsevier.

Malhi, Y., Silman, M., Salinas, N., Bush, M., Meir, P., \& Saatchi, S. (2010). Introduction: Elevation gradients in the tropics: Laboratories for ecosystem ecology and global change research. Global Change Biology, 16, 3171-3175. https://doi.org/10.1111/j.1365-2486.2010.02323.x

Margono, B. A., Potapov, P. V., Turubanova, S., Stolle, F., \& Hansen, M. C. (2014) Primary forest cover loss in Indonesia over 2000-2012. Nature Climate Change, 4, 730-735.

Marshall, A. J., Beaudrot, L., \& Wittmer, H. (2014). Responses of primates and other frugivorous vertebrates to plant resource variability over space and time at Gunung Palung National Park. International Journal of Primatology, 35, 1178-1201. https://doi.org/10.1007/s10764-014-9774-4

Moles, A. T., \& Ollerton, J. (2016). Is the notion that species interactions are stronger and more specialized in the tropics a zombie idea? Biotropica, 48(2), 141-145.

Moles, A. T., Wallis, I. R., Foley, W. J., Warton, D. I., Stegen, J. C., Bisigato, A. J., ... Prior, L. D. (2011). Putting plant resistance traits on the map: A test of the idea that plants are better defended at lower latitudes. New Phytologist, 191, 777-788. https://doi.org/10.1111/j.1469-8137.2011.03732.x

Mugerwa, B., Sheil, D., Ssekiranda, P., van Heist, M., \& Ezuma, P. (2013). A camera trap assessment of terrestrial vertebrates in Bwindi Impenetrable National Park, Uganda. African Journal of Ecology, 51, 21-31. https://doi.org/10.1111/aje.12004

Pacifici, M., Foden, W. B., Visconti, P., Watson, J. F. M., Butchart, S. H. M., Kovacs, K. M., ... Rondinini, C. (2015). Assessing species vulnerability to climate change. Nature Climate Change, 5, 215-225. https://doi. org/10.1038/nclimate2448

Pimm, S. L., Jenkins, C. N., Abell, R., Brooks, T. M., Gittleman, J. L., Joppa, L. N., ... Sexton, J. O. (2014). The biodiversity of species and their rates of extinction, distribution, and protection. Science, 344, 1246752. https://doi.org/10.1126/science.1246752

Pollock, K. H. (1982). A capture-recapture design robust to unequal probability of capture. Journal of Wildlife Management, 46(3), 752-757.

Record, S., Strecker, A., Tuanmu, M.-N., Beaudrot, L., Zarnetske, P., Belmaker, J., ... Bosso, L. (2018). Does scale matter? A systematic review of incorporating biological realism when predicting changes in species distributions. PLOS ONE, 13(4), e0194650.

R Development Core Team. (2016). R: A language and environment for statistical computing. Vienna, Austria: R Foundation for Statistical Computing.

Roslin, T., Hardwick, B., Novotny, V., Petry, W. K., Andrew, N. R., Asmus, A., ... Slade, E. M. (2017). Higher predation risk for insect prey at low latitudes and elevations. Science, 356, 742-744. https://doi. org/10.1126/science.aaj1631

Rowe, K. C., Rowe, K. M. C., Tingley, M. W., Koo, M. S., Patton, J. L., Conroy, C. J., ... Moritz, C. (2015). Spatially heterogeneous impact of climate change on small mammals of montane California. Proceedings of the Royal Society B: Biological Sciences, 282(1799), 20141857.

Royle, J. A., \& Dorazio, R. M. (2008). Hierarchical model and inference in ecology: The analysis of data from populations, metapopulations, and communities. San Diego, CA: Academic Press.

Royle, J. A., \& Nichols, J. D. (2003). Estimating abundance from repeated presence-absence data or point counts. Ecology, 84, 777-790. https:// doi.org/10.1890/0012-9658(2003)084[0777:EAFRPA]2.0.CO;2

Schemske, D. W., Mittelbach, G. G., Cornell, H. V., Sobel, J. M., \& Roy, K. (2009). Is there a latitudinal gradient in the importance of biotic interactions? Annual Review of Ecology Evolution and Systematics, 40, 245-269.

Schipper, J., Chanson, J. S., Chiozza, F., Cox, N. A., Hoffmann, M., Katariya, V., ... Young, B. E. (2008). The status of the world's land and marine mammals: Diversity, threat, and knowledge. Science, 322, 225-230. https://doi.org/10.1126/science.1165115

Schloss, C. A., Nunez, T. A., \& Lawler, J. J. (2012). Dispersal will limit ability of mammals to track climate change in the Western Hemisphere.
Proceedings of the National Academy of Sciences USA, 109, 8606-8611. https://doi.org/10.1073/pnas.1116791109

Sheil, D. (2016). Disturbance and distributions: Avoiding exclusion in a warming world. Ecology and Society, 21(1), https://doi.org/10.5751/ ES-07920-210110

Strauss, S. Y., Webb, C. O., \& Salamin, N. (2006). Exotic taxa less related to native species are more invasive. Proceedings of the Academy of Natural Sciences of Philadelphia, 103, 5841-5845.

Sundqvist, M. K., Sanders, N. J., \& Wardle, D. A. (2013). Community and ecosystem responses to elevational gradients: Processes, mechanisms, and insights for global change. Annual Review of Ecology, Evolution, and Systematics, 44(44), 261-280. https://doi.org/10.1146/ annurev-ecolsys-110512-135750

Svenning, J. C., Gravel, D., Holt, R. D., Schurr, F. M., Thuiller, W., Munkemuller, T., ... Normand, S. (2014). The influence of interspecific interactions on species range expansion rates. Ecography, 37, 11981209. https://doi.org/10.1111/j.1600-0587.2013.00574.x

Swenson, N. G. (2013). The assembly of tropical tree communities-The advances and shortcomings of phylogenetic and functional trait analyses. Ecography, 36, 264-276. https://doi.org/10.1111/j.16000587.2012.00121.x

TEAM Network. (2011). Terrestrial vertebrate monitoring protocol. In TEAM standardized monitoring protocols, TEAM Website. Retrieved from https://wildlifeinsights.org/team-network

Thompson, R. M., Beardall, J., Beringer, J., Grace, M., \& Sardina, P. (2013). Means and extremes: Building variability into community-level climate change experiments. Ecology Letters, 16, 799-806. https://doi. org/10.1111/ele.12095

Urban, M. C., Bocedi, G., Hendy, A. P., Mihoub, J. B., Pe'er, G., Singer, A., ... Travis, J. M. J. (2016). Improving the forecast for biodiversity under climate change. Science, 353(6304), aad8466. https://doi. org/10.1126/science.aad8466.

Urban, M. C., Tewksbury, J. J., \& Sheldon, K. S. (2012). On a collision course: Competition and dispersal differences create no-analogue communities and cause extinctions during climate change. Proceedings of the Royal Society B: Biological Sciences, 279, 20722080. https://doi.org/10.1098/rspb.2011.2367

Urban, M. C., Zarnetske, P. L., \& Skelly, D. K. (2013). Moving forward: Dispersal and species interactions determine biotic responses to climate change. Climate Change and Species Interactions: Ways Forward, 1297, 44-60.

Uriarte, M., Swenson, N. G., Chazdon, R. L., Comita, L. S., Kress, W. J., Erickson, D., ... Thompson, J. (2010). Trait similarity, shared ancestry and the structure of neighbourhood interactions in a subtropical wet forest: Implications for community assembly. Ecology Letters, 13, 1503-1514. https://doi.org/10.1111/j.1461-0248.2010.01541.x

Vasseur, D. A., DeLong, J. P., Gilbert, B., Greig, H. S., Harley, C. D. G., McCann, K. S., ... O'Connor, M. I. (2014). Increased temperature variation poses a greater risk to species than climate warming. Proceedings of the Royal Society B: Biological Sciences, 281(1779), 20132612. https://doi.org/10.1098/rspb.2013.2612

Warren, R. J., \& Chick, L. (2013). Upward ant distribution shift corresponds with minimum, not maximum, temperature tolerance. Global Change Biology, 19, 2082-2088. https://doi.org/10.1111/gcb.12169

Welbergen, J. A., Klose, S. M., Markus, N., \& Eby, P. (2008). Climate change and the effects of temperature extremes on Australian flying-foxes. Proceedings of the Royal Society B: Biological Sciences, 275(1633), 419425. https://doi.org/10.1098/rspb.2007.1385

Wisz, M. S., Pottier, J., Kissling, W. D., Pellissier, L., Lenoir, J., Damgaard, C. F., ... Svenning, J. C. (2013). The role of biotic interactions in shaping distributions and realised assemblages of species: Implications for species distribution modelling. Biological Reviews, 88, 15-30. https://doi.org/10.1111/j.1469-185X.2012.00235.x

Wright, S. J. (1996). Phenological responses to seasonality in tropical forest plants. In S. S. Mulkey, R. L. Chazdon, \& A. P. Smith, (Eds.), Tropical forest plant ecophysiology (pp. 440-460). New York, NY: Chapman \& Hall. 
Yackulic, C. B., Nichols, J. D., Reid, J., \& Der, R. (2015). To predict the niche, model colonization and extinction. Ecology, 96, 16-23. https:// doi.org/10.1890/14-1361.1

\section{BIOSKETCH}

LYDIA BEAUDROT is a community and macroecologist whose research focuses on understanding the determinants of community composition, particularly for tropical mammals. BEAUDROT Combines observational data with statistical modelling approaches to investigate questions at the interface of ecological theory and conservation biology.

\section{SUPPORTING INFORMATION}

Additional supporting information may be found online in the Supporting Information section at the end of the article.

How to cite this article: Beaudrot L, Acevedo MA, Lessard J-P, et al. Local temperature and ecological similarity drive distributional dynamics of tropical mammals worldwide. Global Ecol Biogeogr. 2019;28:976-991. https://doi.org/10.1111/ $\underline{\text { geb.12908 }}$ 